\title{
De and re-levering betas with risky debt
}

\author{
Marko Volker Krause ${ }^{1}$
}

Received: 24 January 2018/ Accepted: 19 June 2018/Published online: 3 July 2018

(C) The Author(s) 2018

\begin{abstract}
De- and re-levering betas is important to obtain discount rates for assets that are not publicly traded. A de- and re-levering procedure is around for the case of risk-free debt. The procedure for risky debt is much less clear even under very simplifying assumptions. In this paper, I concretize and extend the procedure for deand re-levering of betas for companies with risky debt. I derive procedures for different assumptions on the taxation of a cancellation of debt (COD) and for different assumptions regarding the distribution of losses on interest and principal payments. With a tax on the COD I obtain known results. However, without taxes on a COD, the distribution of losses on interest and principal payments matters and equations differ markedly for different assumptions on the assignment of losses to interest and principal payments. Furthermore, using a procedure that does not fit the COD treatment is likely to lead to substantial deviations for de- and re-levered betas from their correct values.
\end{abstract}

Keywords Default risk - Tax treatment of default $\cdot$ Betas - Leverage

JEL Classification G12 · G31 · G32 · G33

\section{Introduction}

I build on the work of Krause and Lahmann (2017) and use it to extend their analysis for a de- and re-levering procedure for equity betas. I include interest and principal prioritization as additional cases, and I also discuss the case of constant leverage and an infinite horizon.

Marko Volker Krause

marko.krause@capco.com

1 Capco-The Capital Markets Company GmbH, Opernplatz 14, 60313 Frankfurt, Germany 
The main objective and contribution of this paper is to show how betas can be deand re-levered when debt is risky and when different assumptions on the treatment of a cancellation of debt (COD) are made. The usual equations on de- and relevering betas with risky debt implicitly assume that a COD is taxed as for example in Arzac and Glosten (2005). But as Krause and Lahmann (2017) mention, there are cases in which a COD remains untaxed. Furthermore, the assumption of a taxed COD is often not formally stated. However, presented equations change significantly when the assumption of taxes on a COD is dropped and when debt is risky.

The pricing framework builds mainly on the findings of Modigliani and Miller (1958) and Modigliani and Miller (1963). Additionally, Miles and Ezzell (1980) and Miles and Ezzell (1985) derive risk-adjusted discount rates in a multiperiod setting with corporate taxes and with constant leverage. In the more recent literature, several authors include the taxation of a COD into their analyses of corporations with risky debt [see e.g., (Kruschwitz and Löffler 2006; Cooper and Nyborg 2008; Blaufus and Hundsdoerfer 2008)].

Eventually, the de- and re-levering procedure relies on an expected return equation from an asset pricing model. This model does not need to be the classic mean-variance CAPM. A more general framework that relies on a stochastic discount factor is presented in Cochrane (2005) and can also be used.

I continue to introduce the basic notation for the single-period case. I present the beta equation for risk-free debt. Continuing with risky debt, I divide into the case of a taxation of a COD and the one without a taxation of a COD. At the end of the next section, I summarize the equations, discuss them and give a short example on possible miscalculations through applying the incorrect equation. In Sect. 3, I briefly discuss the infinite horizon case with constant leverage, which, under simplifying assumptions, is similar to the single-period case. Section 4 summarizes the paper.

\section{Levered and unlevered beta in a single-period setting}

\subsection{On COD taxation}

According to Schwartzman and Brandstetter (2015), a US company's forgiven or cancelled amount of debt from a bankruptcy or insolvency has to be recognized as gross income. ${ }^{1}$ The COD is included in taxable income. However, there are several important exceptions from the general rule, most importantly bankruptcy and insolvency exclusions.

For bankruptcy, which is defined as a case under Title 11 of the US Code, discharges of indebtedness under "Chapter 11 reorganization, Chapter 7 liquidations, and Chapter 13 bankruptcy proceedings" [see Schwartzman and Brandstetter (2015)] are excluded from taxable COD income. The discharge has to be ordered by a court or approved by a court. The COD is not included in gross income, but so

\footnotetext{
1 See also the publication of the IRS (IRS 2012, p. 26).
} 
called tax attributes "certain losses, credits, and basis of property must be reduced by the amount of excluded income (but not below zero)" (IRS 2012, p. 26).

Insolvency, defined as liabilities in excess of the company's market value at the time right before the discharge, is also excluded from COD income. Only the insolvent amount can be excluded, and, again, certain tax attributes must be reduced. The reduction of tax attributes leads to a partial postponment of the tax on a COD instead of a full forgiveness IRS (2012) p. $26 \mathrm{ff}$.

The items mentioned above can only give a general picture. For more information please refer to the documentation from the Internal Revenue Service, for example, to IRS (2012) or to Schwartzman and Brandstetter (2015). Following the prior literature on pricing with and without a COD taxation, I will separately analyze the two extreme cases, the one in which a COD is taxed whenever debt is cancelled and the one in which it is never taxed. More elaborate models can be developed upon what is provided here.

\subsection{Basic equations}

I start with a simple setting with two points in time as in Krause and Lahmann (2017). I use the same notation and assumptions as in the mentioned paper. The single-period analysis has the advantages that additional assumptions on what happens after default are not necessary and that a simple notation without time subscripts is sufficient. Using simplifying assumptions, the infinite horizon version does not differ from the single period results as will be shown later. The starting point of the single-period analysis is the identity of (expected) cash flows:

$$
E\left[\mathrm{FCF}^{\mathrm{L}}\right]=E[\mathrm{ECF}]+E[\mathrm{Int}+\mathrm{PP}]=E[\mathrm{FCF}]+E[\mathrm{TS}] .
$$

Levered free cash flows $\mathrm{FCF}^{\mathrm{L}}$ are equal to the sum of equity cash flows ECF, as well as debt cash flows, which, in turn, consist of interest payments Int and principal payments PP. Alternatively, levered free cash flows are equal to unlevered free cash flows FCF and tax savings TS. Taking expected values through the operator $E[\cdot]$ keeps the identity. Equation (1) can be restated using values and returns

$$
S \times E\left[R^{\mathrm{E}}\right]+D \times E\left[R^{\mathrm{D}}\right]=(S+D-\mathrm{VTS}) \times E\left[R^{\mathrm{U}}\right]+E[\mathrm{TS}],
$$

in which

$$
V^{\mathrm{U}}=V^{\mathrm{L}}-\mathrm{VTS}=S+D-\mathrm{VTS},
$$

here $V^{\mathrm{L}}$ is the value of the levered firm, $V^{\mathrm{U}}$ the value of the unlevered firm ${ }^{2}, S$ the value of equity, $D$ the value of debt, and VTS the value of tax savings. Furthermore, $R^{\mathrm{E}}$ is the return on (levered) equity, $R^{\mathrm{D}}$ is the return on debt, and $R^{\mathrm{U}}$ is the return on unlevered equity. In the expected value operator they are the respective expected returns. I use $R$ for gross returns and $r$ for net returns, where $R=1+r$. Values can be obtained by discounting expected cash flows, with $S=\frac{E[\mathrm{ECF}]}{E\left[R^{\mathrm{E}}\right]}$ for equity, $D=$

\footnotetext{
${ }^{2}$ The assets of the unlevered firm are the same as in the levered case, just the financing is different.
} 
$\frac{E[\mathrm{Int}+\mathrm{PP}]}{E\left[R^{\mathrm{D}}\right]}$ for debt and $V^{\mathrm{U}}=\frac{E[\mathrm{FCF}]}{E\left[R^{\mathrm{U}}\right]}$ for the value of the unlevered firm. Having defined the basic notation and relations, I turn to the risk-free case.

\subsection{Risk-free debt and risk-free tax savings}

I start with the simple but least relevant practical case for corporate valuations: riskfree debt. Since a COD will never happen with risk-free debt, its tax treatment does not play a role. I assume that the firm generates enough taxable income before interest payments to be able to fully deduct interest payments and to qualify for full interest tax savings. Then, all tax savings are equal to the risk-free interest payments times the tax rate on corporate profits $\tau$ : TS $=\tau \times$ Int $=\tau \times r^{\mathrm{f}} \times D$. Debt yields the risk-free interest rate $r^{f}$. I stress here that risk-free debt is a very special case, in which the firm is able to pay off all of its debt obligations in any future state. Leverage potentially affects the firms profitability so that, with higher leverage, riskfree debt becomes more and more unlikely. Compare Krause and Lahmann (2015) for a numerical example.

When debt is risk-free and the mean-variance CAPM is used to obtain expected returns, the following equation shows the relation of the levered and unlevered beta, i.e., of $\beta_{\mathrm{E}, \mathrm{M}}$ and $\beta_{\mathrm{U}, \mathrm{M}}$ :

$$
\beta_{\mathrm{E}, \mathrm{M}}=\left(1+\frac{D}{S} \times \frac{1+r^{\mathrm{f}} \times(1-\tau)}{R^{\mathrm{f}}}\right) \times \beta_{\mathrm{U}, \mathrm{M}} .
$$

Appendix 1 shows the derivation Eq. (4). Equation (32) in Arzac and Glosten (2005) is similar to Eq. (4) when their $r^{\mathrm{D}}$, a discount rate for debt, is replaced by $r^{\mathrm{f}}$. Their derivation is actually done in an infinite horizon setting. However, Eq. (4) is the result of a single-period analysis. Adding periods does not add much to the analysis.

The term $\frac{1+r^{f} \times(1-\tau)}{R^{f}}$ is due to tax savings. With a zero tax rate this term equals one. For $r^{f}>0$ and with the tax rate between zero and one (inclusive) this term is less than one. For $r^{f}<0$ the term is greater than one.

Equation (4) also shows that higher debt relative to equity, i.e., a higher leverage, scales up the levered beta. With higher leverage relatively more debt payments have to be made from the cash flows coming from the firm's assets. The remaining diminished cash flows go to equity holders. The return of those cash flows have a higher absolute value of the beta than before the increase in leverage. For positive unlevered beta the levered beta increases. If the unlevered beta is negative, the levered beta decreases. Appendix 1 shows how this occurs.

A higher tax rate decreases the levered beta. A higher tax rate increases tax savings and the value of them, which counters the effect of leverage, i.e., systematic risk is decreased through the presence of risk-free tax savings. Given that debt is risk-free, the risk-free tax savings are earned by equity holders. Therefore, tax savings increase the value of equity.

Equation (4) can also be stated in terms of leverage. This gives 


$$
\beta_{\mathrm{E}, \mathrm{M}}=\frac{1}{1-l} \times\left(1-l \times \frac{\tau \times r^{\mathrm{f}}}{R^{\mathrm{f}}}\right) \times \beta_{\mathrm{U}, \mathrm{M}} .
$$

A zero risk-free rate would also take out the tax effect. In this case interest payment would be zero so that there are no tax savings-just as for a zero tax rate:

$$
\beta_{\mathrm{E}, \mathrm{M}}=\frac{1}{1-l} \times \beta_{\mathrm{U}, \mathrm{M}}
$$

After this introduction for risk-free debt, I turn to the more relevant case in the coporate world, the case of risky debt.

\subsection{Risky debt}

For risky debt the COD treatment is important. From Krause and Lahmann (2017), I restate the pricing equations for the value of the tax savings VTS for the different cases. Without (superscript NC) and with (superscript C) a tax on debt cancellation the tax savings are, respectively,

$$
\begin{gathered}
\mathrm{TS}^{\mathrm{NC}}=\tau \times \text { Int, } \\
\mathrm{TS}^{\mathrm{C}}=\tau \times \text { Int }-\tau \times C,
\end{gathered}
$$

here $\tau$ is the deterministic tax rate on corporate profits, and $C$ is the amount of debt that is cancelled, i.e., the losses on the principal $D$ - the COD. When $C$ is taxed, the whole tax savings are reduced by $\tau \times C$. Here it is assumed that $\tau \times C$ can actually be paid by the defaulting firm. Furthermore, interest payments can be expressed as

$$
\text { Int }=r^{\mathrm{c}} \times D-(L-C),
$$

in which $L$ are the total losses on debt, i.e., losses on interest $L^{\text {Int }}$ and on principal payments $C$, and $r^{\mathrm{c}}$ is the coupon rate. ${ }^{3}$ According to Krause and Lahmann (2017), the values of the tax savings are then

$$
\begin{gathered}
\operatorname{VTS}^{\mathrm{NC}}=\tau \times \frac{r^{\mathrm{f}} \times D}{R^{\mathrm{f}}}+\tau \times p(C) \\
\operatorname{VTS}^{\mathrm{C}}=\tau \times \frac{r^{\mathrm{f}} \times D}{R^{\mathrm{f}}} .
\end{gathered}
$$

The term $p(C)$ is the price of the COD, i.e., $p(\cdot)$ is used as a pricing operator. The basis for further derivations is the identity

$$
S \times E\left[R^{\mathrm{E}}\right]+D \times E\left[R^{\mathrm{D}}\right]=(S+D-\mathrm{VTS}) \times E\left[R^{\mathrm{U}}\right]+E[\mathrm{TS}] .
$$

I continue with the case of taxation of a COD.

\footnotetext{
${ }^{3}$ For a zero coupon bond it is the implicit coupon rate.
} 


\subsubsection{Taxes on debt cancellation}

I use Eq. (12) and substitute in the respective expression for the value of the tax shield and the tax savings from Eqs. (11) and (8):

$$
\begin{aligned}
S \times & E\left[R^{\mathrm{E}}\right]+D \times E\left[R^{\mathrm{D}}\right]=\left(S+D-\tau \times \frac{r^{\mathrm{f}} \times D}{R^{\mathrm{f}}}\right) \times E\left[R^{\mathrm{U}}\right]+\tau \\
& \times\left(r^{\mathrm{c}} \times D-E[L-C]\right)-\tau \times E[C] .
\end{aligned}
$$

The $\tau \times E[C]$ terms cancel on the rhs and $r^{\mathrm{c}} \times D-E[L]=D \times E\left[r^{\mathrm{D}}\right]$ so that the equation turns to

$$
S \times E\left[R^{\mathrm{E}}\right]+D \times\left(1+E\left[r^{\mathrm{D}}\right] \times(1-\tau)\right)=\left(S+D-\tau \times \frac{r^{\mathrm{f}} \times D}{R^{\mathrm{f}}}\right) \times E\left[R^{\mathrm{U}}\right] .
$$

I use the expected return equation for the mean-variance $\mathrm{CAPM}^{4}$ of the form

$$
E\left[R^{\mathrm{i}}\right]=R^{\mathrm{f}}+\beta_{\mathrm{i}, \mathrm{M}} \times\left(E\left[\mathrm{R}^{\mathrm{M}}\right]-R^{\mathrm{f}}\right),
$$

for the expected return, in which $i$ stands for the return on levered equity, on unlevered equity, on tax savings or on debt. The return $R^{\mathrm{M}}$ is the return on the market portfolio. I obtain

$$
\begin{aligned}
S & \times\left(R^{\mathrm{f}}+\beta_{\mathrm{E}, \mathrm{M}} \times\left(E\left[R^{\mathrm{M}}\right]-R^{\mathrm{f}}\right)\right)+D \times\left(1+\left(R^{\mathrm{f}}+\beta_{\mathrm{D}, \mathrm{M}} \times\left(E\left[\mathrm{R}^{\mathrm{M}}\right]-R^{\mathrm{f}}\right)-1\right) \times(1-\tau)\right) \\
& =\left(S+D-\tau \times \frac{r^{f} \times D}{R^{f}}\right) \times\left(R^{f}+\beta_{U, M} \times\left(E\left[R^{M}\right]-R^{f}\right)\right) .
\end{aligned}
$$

This expression can be simplified to

$$
S \times \beta_{\mathrm{E}, \mathrm{M}}+D \times \beta_{\mathrm{D}, \mathrm{M}} \times(1-\tau)=\left(S+D-\tau \times \frac{r^{\mathrm{f}} \times D}{R^{\mathrm{f}}}\right) \times \beta_{\mathrm{U}, \mathrm{M}} .
$$

Rearranging yields

$$
\beta_{\mathrm{E}, \mathrm{M}}=\left(1+\frac{D}{S} \times \frac{1+r^{\mathrm{f}} \times(1-\tau)}{R^{\mathrm{f}}}\right) \times \beta_{\mathrm{U}, \mathrm{M}}-\beta_{\mathrm{D}, \mathrm{M}} \times \frac{D}{S} \times(1-\tau) .
$$

When debt has no systematic risk, i.e., when $\beta_{\mathrm{D}, \mathrm{M}}=0$, the equation reduces to the one with risk-free debt. Again, Arzac and Glosten (2005) have the same result in their Equation (32). However, there is no reference to the treatment of debt cancellation. The following will show that the assumption of taxes on a COD is crucial to obtain this equation. Without it, valuations change and with them the de- und relevering procedure. It is reasonable to expect the beta for debt to have the same sign as the one for equity. Furthermore, we usually expect positive equity betas together

\footnotetext{
${ }^{4}$ In (Cochrane 2005, p. 17 and p. 19) a more general equation for an expected return equation using a stochastic discount factor is presented. In this case, the beta factor depends on how the stochastic discount factor is specified as a function of market data. The CAPM is a special case in which the stochastic discount factor is a linear function of the market return.
} 
with positive debt betas. That means when the market is doing well as whole, debt contracts will also do better. When the market is not doing well, for example in recessions, there will be more defaults and the return on debt will also be lower. With a positive beta for debt, the additional debt-related term in Eq. (18) reduces the levered beta, which counters the effect of the first term on the rhs of the equation, which increases the levered beta with more leverage.

\subsubsection{No taxes on debt cancellation}

Proportional loss distribution according to contractual debt payments Krause and Lahmann (2017) derive an equation for the tax shield value for the case of a proportional loss distribution. Proportional loss distribution means that total losses $L$ are distributed proportionally or pro rata according to the contractually agreed debt payments. Losses on interest and principal payments are, respectively, $L^{\mathrm{Int}}=$ $L \times \frac{r^{\mathrm{c}}}{R^{\mathrm{c}}}$ and $C=L \times \frac{1}{R^{\mathrm{c}}}$. The equation for the value of the tax shield is

$$
\mathrm{VTS}^{\mathrm{NC}}=\tau \times \frac{r^{\mathrm{c}} \times D}{R^{\mathrm{c}}}
$$

Tax savings are given by

$$
\mathrm{TS}=\tau \times\left(r^{\mathrm{c}} \times D-L \times \frac{r^{\mathrm{c}}}{R^{\mathrm{c}}}\right) .
$$

I substitute both equations into Eq. (12) and obtain:

$$
S \times E\left[R^{\mathrm{E}}\right]+D \times E\left[R^{\mathrm{D}}\right]=\left(S+D-\tau \times \frac{r^{\mathrm{c}} \times D}{R^{\mathrm{c}}}\right) \times E\left[R^{\mathrm{U}}\right]+\tau \times r^{\mathrm{c}} \times D-\tau \times E[L] \times \frac{r^{\mathrm{c}}}{R^{\mathrm{c}}} .
$$

I rewrite the term on the rhs: $\tau \times r^{c} \times D-\tau \times E[L] \times \frac{r^{c}}{R^{c}}=\tau \times r^{c} \times D \times \frac{E\left[R^{D}\right]}{R^{c}}$. I substitute this into the prior equation to obtain

$$
S \times E\left[R^{\mathrm{E}}\right]+D \times E\left[R^{\mathrm{D}}\right] \times\left(1-\frac{\tau \times r^{\mathrm{c}}}{R^{\mathrm{c}}}\right)=\left(S+D-\tau \times \frac{r^{\mathrm{c}} \times D}{R^{\mathrm{c}}}\right) \times E\left[R^{\mathrm{U}}\right] .
$$

Now, I use the expected return equations from the mean-variance CAPM:

$$
\begin{aligned}
S & \times\left(R^{\mathrm{f}}+\beta_{\mathrm{E}, \mathrm{M}} \times\left(E\left[R^{\mathrm{M}}\right]-R^{\mathrm{f}}\right)\right)+D \times\left(R^{\mathrm{f}}+\beta_{\mathrm{D}, \mathrm{M}} \times\left(E\left[R^{\mathrm{M}}\right]-R^{\mathrm{f}}\right)\right) \times\left(1-\frac{\tau \times r^{\mathrm{c}}}{R^{\mathrm{c}}}\right) \\
& =\left(S+D-\tau \times \frac{r^{\mathrm{c}} \times D}{R^{\mathrm{c}}}\right) \times\left(R^{\mathrm{f}}+\beta_{\mathrm{U}, \mathrm{M}} \times\left(E\left[R^{\mathrm{M}}\right]-R^{\mathrm{f}}\right)\right) .
\end{aligned}
$$

This simplifies to 


$$
S \times \beta_{\mathrm{E}, \mathrm{M}}+D \times \beta_{\mathrm{D}, \mathrm{M}} \times\left(1-\frac{\tau \times r^{\mathrm{c}}}{R^{\mathrm{c}}}\right)=\left(S+D-\tau \times \frac{r^{\mathrm{c}} \times D}{R^{\mathrm{c}}}\right) \times \beta_{\mathrm{U}, \mathrm{M}} .
$$

Rearranging for the levered beta I obtain

$$
\beta_{\mathrm{E}, \mathrm{M}}=\left(1+\frac{D}{S} \times \frac{1+r^{\mathrm{c}} \times(1-\tau)}{R^{\mathrm{c}}}\right) \times \beta_{\mathrm{U}, \mathrm{M}}-\beta_{\mathrm{D}, \mathrm{M}} \times \frac{D}{S} \times \frac{1+r^{\mathrm{c}} \times(1-\tau)}{R^{\mathrm{c}}} .
$$

or

$$
\beta_{\mathrm{E}, \mathrm{M}}=\beta_{\mathrm{U}, \mathrm{M}}+\left(\beta_{\mathrm{U}, \mathrm{M}}-\beta_{\mathrm{D}, \mathrm{M}}\right) \times \frac{D}{S} \times \frac{1+r^{\mathrm{c}} \times(1-\tau)}{R^{\mathrm{c}}} .
$$

In most cases, the beta for the unlevered firm is bigger than the one for debt because of priorities of debt cash flows to be paid to debt holders. That means $\beta_{\mathrm{U}, \mathrm{M}}-\beta_{\mathrm{D}, \mathrm{M}}$ is usually positive and with that the levered beta is greater than the unlevered betasomething that one would intuitively expect. In the less likely case, if $\beta_{\mathrm{U}, \mathrm{M}}<\beta_{\mathrm{D}, \mathrm{M}}$, then $\beta_{\mathrm{U}, \mathrm{M}}-\beta_{\mathrm{D}, \mathrm{M}}<0$, and the levered beta is less than the unlevered beta.

Loss distribution not proportional to contractual debt payments As Krause and Lahmann (2015) show, with a pro rata loss distribution according to contractual interest and principal payments, the expected rate of return on debt, i.e., the discount rate on debt $E\left[R^{\mathrm{D}}\right]$, is equal to a weighted average of the expected rates of return on its components, i.e., the one on interest $E\left[R^{\mathrm{Int}}\right]$ and the one on principal payments $E\left[R^{\mathrm{PP}}\right]$. Notice that $p(\mathrm{Int})=\frac{E[\mathrm{Int}]}{E\left[R^{\mathrm{Int}]}\right.}$ and $p(\mathrm{PP})=\frac{E[\mathrm{PP}]}{E\left[R^{\mathrm{PP}}\right]}$ define the discount rates for interest and principal payments. Krause and Lahmann (2015) show that, with interest or principal prioritization, expected rates of return on debt, interest and principal payments regularly differ. Without a COD taxation, tax savings are just interest payments scaled by the tax rate. Thus, the rate of return and the expected rate of return on interest payments and on tax savings are equal: $E\left[R^{\mathrm{TS}}\right]=E\left[R^{\mathrm{Int}} .^{5}\right.$ The expected return on debt as a weighted average of the expected returns on interest and principal payments is

$$
\begin{aligned}
E\left[R^{\mathrm{D}}\right] & =\frac{E[\mathrm{Int}]+E[\mathrm{PP}]}{D} \\
& =E\left[R^{\mathrm{Int}}\right] \times \frac{p(\mathrm{Int})}{D}+E\left[R^{\mathrm{PP}}\right] \times \frac{p(\mathrm{PP})}{D} .
\end{aligned}
$$

Since $D=p(\mathrm{Int})+p(\mathrm{PP})$ and values are positive, the weights $\frac{p(\mathrm{Int})}{D}$ and $\frac{p(\mathrm{PP})}{D}$ are positive and add up to one. Due to this relation, possible relations of the three expected returns on debt cash flows are:

$$
\begin{gathered}
E\left[R^{\mathrm{TS}}\right]=E\left[R^{\mathrm{Int}}\right]<E\left[R^{\mathrm{D}}\right]<E\left[R^{\mathrm{PP}}\right] \\
E\left[R^{\mathrm{TS}}\right]=E\left[R^{\mathrm{Int}}\right]=E\left[R^{\mathrm{D}}\right]=E\left[R^{\mathrm{PP}}\right]
\end{gathered}
$$

\footnotetext{
5 This is true for a certain tax rate, which is assumed herein.
} 


$$
E\left[R^{\mathrm{TS}}\right]=E\left[R^{\mathrm{Int}}\right]>E\left[R^{\mathrm{D}}\right]>E\left[R^{\mathrm{PP}}\right] .
$$

In the mean-variance CAPM, the only parameter that leads to different expected returns between different assets is the beta of an asset. The risk-free rate and the equity premium are not dependent on what kind of asset is regarded. Therefore, the respective betas must follow the same ordering as the expected returns: ${ }^{6}$

$$
\begin{gathered}
\beta_{\mathrm{TS}, \mathrm{M}}=\beta_{\mathrm{Int}, \mathrm{M}}<\beta_{\mathrm{D}, \mathrm{M}}<\beta_{\mathrm{PP}, \mathrm{M}} \\
\beta_{\mathrm{TS}, \mathrm{M}}=\beta_{\mathrm{Int}, \mathrm{M}}=\beta_{\mathrm{D}, \mathrm{M}}=\beta_{\mathrm{PP}, \mathrm{M}} \\
\beta_{\mathrm{TS}, \mathrm{M}}=\beta_{\mathrm{Int}, \mathrm{M}}>\beta_{\mathrm{D}, \mathrm{M}}>\beta_{\mathrm{PP}, \mathrm{M}} .
\end{gathered}
$$

To derive equations for betas, I use Eq. (12). I write it down in the form

$$
S \times E\left[R^{\mathrm{E}}\right]+D \times E\left[R^{\mathrm{D}}\right]=(S+D-\mathrm{VTS}) \times E\left[R^{\mathrm{U}}\right]+\mathrm{VTS} \times E\left[R^{\mathrm{TS}}\right] .
$$

Rearranging, simplifying, and using the CAPM equations leads to

$$
\beta_{\mathrm{E}, \mathrm{M}}=\frac{S+D}{S} \times \beta_{\mathrm{U}, \mathrm{M}}-\frac{D}{S} \times \beta_{\mathrm{D}, \mathrm{M}}+\frac{\mathrm{VTS}}{S} \times\left(\beta_{\mathrm{TS}, \mathrm{M}}-\beta_{\mathrm{U}, \mathrm{M}}\right) .
$$

This equation allows the beta of the tax savings to be different than the one for total debt payments. In what follows, I establish equations that are comparable to the case with the pro rata loss distribution. I write the equation for the tax savings as

$$
\begin{aligned}
\mathrm{VTS} & =p(\mathrm{TS})=\tau \times p(\mathrm{Int}) \\
& =\tau \times p\left(D \times r^{\mathrm{c}}-L^{\mathrm{Int}}\right) \\
& =\tau \times\left(\frac{D \times r^{\mathrm{c}}}{R^{\mathrm{f}}}-p\left(L^{\mathrm{Int}}\right)\right) \\
& =\tau \times \frac{D \times r^{\mathrm{c}}}{R^{\mathrm{c}}} \times\left(\frac{R^{\mathrm{c}}}{R^{\mathrm{f}}}-\frac{p\left(L^{\mathrm{Int}}\right)}{D} \times \frac{R^{\mathrm{c}}}{r^{\mathrm{c}}}\right) \\
& =\tau \times \frac{D r^{\mathrm{c}}}{R^{\mathrm{c}}}+\tau \times\left(p(L) \times \frac{r^{\mathrm{c}}}{R^{\mathrm{c}}}-p\left(L^{\mathrm{Int}}\right)\right) .
\end{aligned}
$$

The first term in the last equality is the equation for the value of the tax savings for a pro rata loss distribution according to contractual debt payments. In case of a pro rata loss distribution, the second term is always zero because then $p\left(L^{\text {Int }}\right)=p(L) \times \frac{R^{\mathrm{c}}}{r^{\mathrm{c}}}$. With loss distributions not proportional to contractual debt payments, the second term is usually not zero. Using that in Eq. (35), I obtain

\footnotetext{
${ }^{6}$ This assumes a positive equity premium. However, a negative premium does not make sense for riskaverse investors.
} 


$$
\begin{aligned}
\beta_{\mathrm{E}, \mathrm{M}}= & \left(1+\frac{D}{S} \times \frac{1+r^{\mathrm{c}} \times(1-\tau)}{R^{\mathrm{c}}}\right) \times \beta_{\mathrm{U}, \mathrm{M}}-\frac{D}{S} \times \beta_{\mathrm{D}, \mathrm{M}}+\frac{D}{S} \times \frac{\tau \times r^{\mathrm{c}}}{R^{\mathrm{c}}} \times \beta_{\mathrm{TS}, \mathrm{M}} \\
& +\frac{F}{S} \times\left(\beta_{\mathrm{TS}, \mathrm{M}}-\beta_{\mathrm{U}, \mathrm{M}}\right),
\end{aligned}
$$

with $F=\tau \times\left(p(L) \times \frac{r^{c}}{R^{c}}-p\left(L^{\text {Int }}\right)\right)$. It turns out that additional information is needed. The beta of the returns on tax savings, i.e., on interest payments is needed as well as the price of losses on interest payments. ${ }^{7}$ I define $\beta_{\Delta \mathrm{TS}, \mathrm{M}}=\beta_{\mathrm{TS}, \mathrm{M}}-\beta_{\mathrm{D}, \mathrm{M}}$. I use this relation and restate Eq. (37) as

$$
\begin{aligned}
\beta_{\mathrm{E}, \mathrm{M}}= & \left(1+\frac{D}{S} \times \frac{1+r^{\mathrm{c}} \times(1-\tau)}{R^{\mathrm{c}}}\right) \times \beta_{\mathrm{U}, \mathrm{M}}-\beta_{\mathrm{D}, \mathrm{M}} \times \frac{D}{S} \times \frac{1+r^{\mathrm{c}} \times(1-\tau)}{R^{\mathrm{c}}} \\
& +\left(\frac{D}{S} \times \frac{\tau \times r^{\mathrm{c}}}{R^{\mathrm{c}}}+\frac{F}{S}\right) \times \beta_{\Delta T S, M}+\frac{F}{S} \times\left(\beta_{\mathrm{D}, \mathrm{M}}-\beta_{\mathrm{U}, \mathrm{M}}\right) .
\end{aligned}
$$

This allows for a better comparability with Eq. (26), i.e., the equation for the pro rata loss distribution according to contractual principal and interest payments. I continue with two prominent cases of loss distributions: interest and principal prioritization.

Loss distribution not proportional to contractual debt payments-interest prioritization A reasonable non-proportional loss distribution is the case of interest prioritization. Interest prioritization means that principal payments will incur losses first. Only if losses are greater than principal payments, interest will incur losses as well. Relation (28) is usually what we expect in this case. ${ }^{8}$ I simplify further. I assume that interest payments will never incur losses. This is a reasonable assumption as long as interest payments are small relative to principal payments, which is what we mainly observe in practice. Under this assumption, interest payments are risk-free so that $L^{\mathrm{Int}}=0$ in any state. The price of losses on interest payments must be zero as well. It follows that the beta of tax savings is zero. The equation for interest payments turns to

$$
\text { Int }=r^{\mathrm{c}} \times D .
$$

and tax savings are

$$
\mathrm{TS}^{\mathrm{NC}}=\tau \times r^{\mathrm{c}} \times D
$$

I discount this risk-free quantity at the risk-free rate, i.e., $E\left[R^{\mathrm{TS}}\right]=R^{\mathrm{f}}$, to obtain the value of the tax savings

$$
\operatorname{VTS}^{\mathrm{NC}}=\tau \times \frac{r^{\mathrm{c}} \times D}{R^{\mathrm{f}}}
$$

Equation (37) condenses to

\footnotetext{
7 The price of losses $p(L)$ can be stated in terms of the debt value, the risk-free rate and the coupon rate.

${ }^{8}$ The other two relations are possible as well but unlikely in practice. For further information refer to Krause and Lahmann (2015).
} 


$$
\beta_{\mathrm{E}, \mathrm{M}}=\left(1+\frac{D}{S} \times \frac{R^{\mathrm{f}}-\tau \times r^{\mathrm{c}}}{R^{\mathrm{f}}}\right) \times \beta_{\mathrm{U}, \mathrm{M}}-\beta_{\mathrm{D}, \mathrm{M}} \times \frac{D}{S} .
$$

As for the pro rata distribution the levered beta is also a combination of the unlevered beta and a scalar as well as the debt beta and a scalar. However, the scalars differ here.

Loss distribution not proportional to contractual debt payments-principal prioritization The other extreme in terms of prioritization is principal payment prioritization. In this case losses are first assigned to interest payments. Only if loses are greater than interest payments, the excess amount of losses is assigned to principal payments. In this case a sensible assumption such as for interest prioritization is not available. Instead, I use Eq. (38) and assumptions on $F$ and the betas. ${ }^{9}$

Given total losses on debt $L$, the losses on interest payments $L^{\text {Int }}$ must be greater than the pro rata share of total losses: $L \times \frac{r^{\mathrm{c}}}{R^{\mathrm{c}}}<L^{\text {Int }}$. Since this is true for any state in which losses occur, the factor $F$ is less than zero: $F=\tau \times\left(p(L) \times \frac{r^{\mathrm{c}}}{R^{\mathrm{c}}}-p\left(L^{\text {Int }}\right)\right)<0$. To parameterize, I assume that the price of losses on interest payments is equal to $p\left(L^{\text {Int }}\right)=p(L) \times\left(\frac{r^{\mathrm{c}}}{R^{\mathrm{c}}}+\alpha\right)$, with $\alpha \in\left(0,1-\frac{r^{\mathrm{c}}}{R^{\mathrm{c}}}\right)$ as the percentage that the price of interest losses is higher than the pro rata share of the price of total losses. Using this parameter in the equation for $F$, I obtain

$$
\begin{gathered}
F=-\tau \times \alpha \times p(L) \\
=-\tau \times \alpha \times D \times \frac{r^{\mathrm{c}}-r^{\mathrm{f}}}{R^{\mathrm{f}}} .
\end{gathered}
$$

The second equality follows from the equation for the coupon rate, ${ }^{10}$ which can be rearranged for the price of losses. Equation (38) turns to

$$
\begin{aligned}
\beta_{\mathrm{E}, \mathrm{M}}= & \left(1+\frac{D}{S} \times \frac{1+r^{\mathrm{c}} \times(1-\tau)}{R^{\mathrm{c}}}\right) \times \beta_{\mathrm{U}, \mathrm{M}}-\beta_{\mathrm{D}, \mathrm{M}} \times \frac{D}{S} \times \frac{1+r^{\mathrm{c}} \times(1-\tau)}{R^{\mathrm{c}}} \\
& +\tau \times \frac{D}{S} \times\left(\frac{r^{\mathrm{c}}}{R^{\mathrm{c}}}-\alpha \times \frac{r^{\mathrm{c}}-r^{\mathrm{f}}}{R^{\mathrm{f}}}\right) \times \beta_{\Delta \mathrm{TS}, \mathrm{M}}+\tau \times \alpha \times \frac{r^{\mathrm{c}}-r^{\mathrm{f}}}{R^{\mathrm{f}}} \times \frac{D}{S} \times\left(\beta_{\mathrm{U}, \mathrm{M}}-\beta_{\mathrm{D}, \mathrm{M}}\right) .
\end{aligned}
$$

Notice that with $\alpha \in\left(0,1-\frac{r^{\mathrm{c}}}{R^{\mathrm{c}}}\right)$, it follows, for the term attached to $\beta_{\Delta \mathrm{TS}, \mathrm{M}}$, that $\frac{r^{\mathrm{f}}}{R^{\mathrm{f}}}<\left(\frac{r^{\mathrm{c}}}{R^{\mathrm{c}}}-\alpha \times \frac{r^{\mathrm{c}}-r^{\mathrm{f}}}{R^{\mathrm{f}}}\right)<\frac{r^{\mathrm{c}}}{R^{\mathrm{c}}} .11$ Furthermore, it is reasonable to assume that $\beta_{\Delta \mathrm{TS}, \mathrm{M}}>0$, i.e., the beta of the returns on tax savings is greater than the one for the returns on debt. Since the return on tax savings and on interest payments are the same, the betas of the two figures are the same as well. With losses first assigned to interest payments, their returns will regularly have a higher beta than the beta for

\footnotetext{
${ }^{9}$ For further discussion on principal prioritization see Krause and Lahmann (2015).

10 The equation is $r^{\mathrm{c}}=r^{\mathrm{f}}+R^{\mathrm{f}} \times \frac{p(L)}{D}$, which is just $D=p\left(D \times\left(1+r^{\mathrm{c}}\right)-L\right)$ rearranged for the coupon rate.

${ }^{11}$ Notice that for risky debt $\frac{r^{\mathrm{f}}}{R^{t}}<\frac{r^{\mathrm{c}}}{R^{\mathrm{c}}}$. To see this multiply by $R^{\mathrm{f}}$ and $R^{\mathrm{c}}$, which are both positive, and simplify. The result is $r^{\mathrm{f}}<r^{\mathrm{c}}$, which must hold for risky debt due to a positive credit risk premium.
} 
returns on principal payments and the one for returns on debt payments as a whole. $^{12}$

In the next subsection, I will compare the differences of the equations more in detail.

\subsection{Overview and discussion}

Table 1 shows an overview of the different cases treated in this paper. Some remarks are in order. For debt returns uncorrelated with market returns $\beta_{\mathrm{D}, \mathrm{M}}=0$, the expected return on debt is equal to the risk free rate: $E\left[R^{\mathrm{D}}\right]=R^{\mathrm{f}}$. However, with risky debt, the coupon rate must be greater than the risk-free rate because the coupon rate must account for the default risk: $r^{\mathrm{c}}>r^{\mathrm{f}}$. This can also be restated as $r^{\mathrm{c}}=r^{\mathrm{f}}+\kappa$, in which $\kappa>0$ is a credit risk premium. Thus, for $\beta_{\mathrm{D}, \mathrm{M}}=0$, the equations for the risk-free case and for the risky case with taxes on a COD are the same. Krause and Lahmann (2017) found that the value of the tax savings for risky debt with taxed COD is the same as if debt is risk-free. However, without taxes on a COD the equations to adjust betas differ through the involvement of the coupon rate and possible other parameters.

A comparison of the equations in Table 1 makes most sense for the purpose of picking the correct equation given the case of the tax treatment and loss distribution. Then, one can evaluate the bias of picking an incorrect equation.

It does not make sense to pick a set of parameters and then try out all of the equations for the different cases intending to evaluate what the outcome would be given the parameters. The reason is that the different cases may be consistent only with different sets of inputs such as leverage and the coupon rate, because the tax assumption may influence the loss distribution.

I look at the factors scaling up and down the unlevered equity betas and the debt betas.

For the first three equations and the fifth equation notice that $1+\frac{D}{S} \times \frac{1+r^{\mathrm{f}} \times(1-\tau)}{R^{\mathrm{f}}}>1+\frac{D}{S} \times \frac{1+r^{\mathrm{c}} \times(1-\tau)}{R^{\mathrm{c}}}$. To see that I rewrite the equations to $-\tau \times$ $\frac{r^{\mathrm{f}}}{R^{\mathrm{f}}}>-\tau \times \frac{r^{\mathrm{c}}}{R^{\mathrm{c}}}$ and divide by $-\tau$ to obtain $\frac{r^{\mathrm{f}}}{R^{\mathrm{f}}}<\frac{r^{\mathrm{c}}}{R^{\mathrm{c}}}$. I multiply by $R^{\mathrm{f}}$ and $R^{\mathrm{c}}$, which are both positive. That leads to $r^{\mathrm{f}} \times\left(R^{\mathrm{f}}+\kappa\right)<\left(r^{\mathrm{f}}+\kappa\right) \times R^{\mathrm{f}}$ which simplifies to $0<\kappa$. The credit risk premium must be positive so that the inequality always holds.

Regarding equations three and four, the inequality $1+\frac{D}{S} \times \frac{1+r^{\mathrm{c}} \times(1-\tau)}{R^{\mathrm{c}}}>1+\frac{D}{S} \times$ $\frac{R^{\mathrm{f}}-\tau \times r^{\mathrm{c}}}{R^{\mathrm{f}}}$ holds only for $r^{\mathrm{c}}>0$.

Regarding the first two equations and the forth one, the inequality $1+\frac{D}{S} \times$ $\frac{1+r^{\mathrm{f}} \times(1-\tau)}{R^{\mathrm{f}}}>1+\frac{D}{S} \times \frac{1+r^{\mathrm{c}} \times(1-\tau)}{R^{\mathrm{f}}}$ always holds. This can be seen using the same simplifying steps as before.

\footnotetext{
12 This is the likely case. Theoretically, it is also possible that this does not hold. The prioritization rules can be transformed into option-like payments. For a more detailed analysis of expected returns on options see Coval and Shumway (2001), and for an analysis with respect to tax savings see Krause and Lahmann (2015).
} 
Table 1 Summary of cases and equations

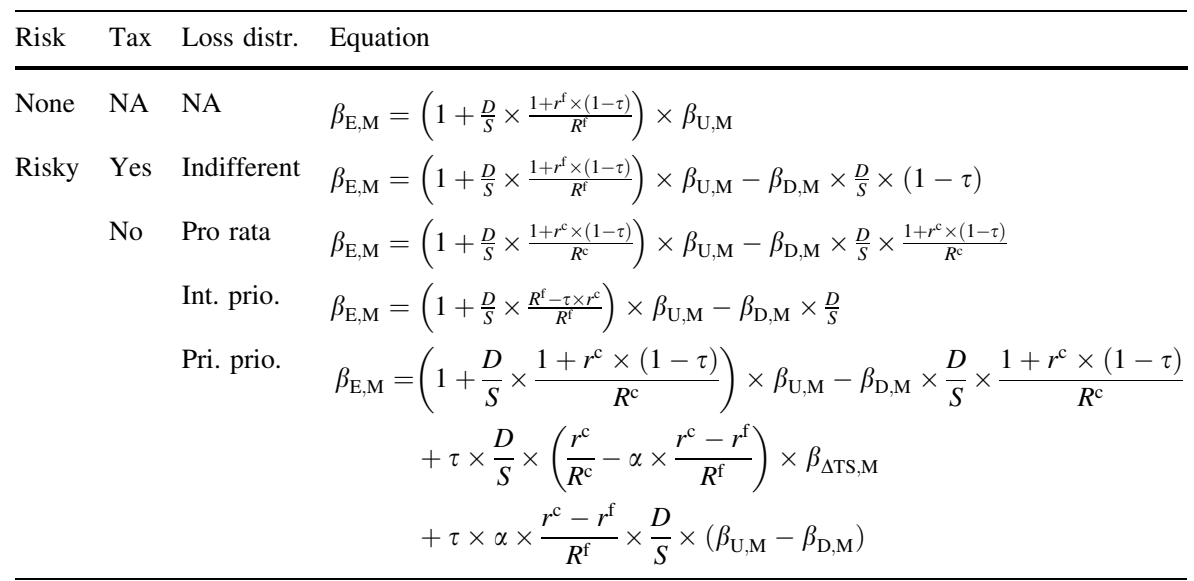

The table shows the equations for de- and re-levering betas for the different cases. The column "Risk" indicates whether debt is risk-free or risky. The column "Tax" indicates whether a tax on a COD is paid or not. The column "Loss distr." indicates how total losses are assumed to be allocated to interest and principal payments. Pro rata loss distribution means that total losses of debt are distributed to interest payments and principal payments according to contractual interest and principal payments. Interest prioritization means that all losses are first assigned to principal payments. The equation for interest prioritization presented here relies on the additional assumption that interest payments never incur losses. Principal prioritization means that all losses are first assigned to interest payments before principal payments are affected

I continue with the terms attached to the debt betas in equation two and three. For those equations $-\frac{D}{S} \times(1-\tau)>-\frac{D}{S} \times \frac{1+r^{c} \times(1-\tau)}{R^{c}}$. To see this, I simplify to $\tau>\tau \times \frac{r^{\mathrm{c}}}{R^{\mathrm{c}}}$, divide by $\tau$ and multiply by $R^{\mathrm{c}}$ to obtain $R^{\mathrm{c}}>r^{\mathrm{c}}$ or $1>0$, which always holds. Regarding equations three and four, for $r^{\mathrm{c}}>0$ the inequality $-\frac{D}{S}<-$ $\frac{D}{S} \times \frac{1+r^{\mathrm{c}} \times(1-\tau)}{R^{\mathrm{c}}}$ holds.

Thus, for a positive coupon rate

$$
1+\frac{D}{S} \times \frac{1+r^{\mathrm{f}} \times(1-\tau)}{R^{\mathrm{f}}}>1+\frac{D}{S} \times \frac{1+r^{\mathrm{c}} \times(1-\tau)}{R^{\mathrm{c}}}>1+\frac{D}{S} \times \frac{R^{\mathrm{f}}-\tau \times r^{\mathrm{c}}}{R^{\mathrm{f}}},
$$

and

$$
-\frac{D}{S} \times(1-\tau)>-\frac{D}{S} \times \frac{1+r^{\mathrm{c}} \times(1-\tau)}{R^{\mathrm{c}}}>-\frac{D}{S} .
$$

That means for a positive coupon rate and for positive betas for debt and unlevered equity, the levered beta will be smaller going down the equations in Table 1 until the forth equation.

For positive betas debt betas may be larger than unlevered equity betas. For high debt betas and since the term including the debt beta is subtracted, the beta for levered equity may even be less than the one for unlevered equity, i.e., $\beta_{\mathrm{E}, \mathrm{M}}<\beta_{\mathrm{U}, \mathrm{M}}$. 
I will have a quick look at $\beta_{\mathrm{D}, \mathrm{M}}$ when $\beta_{\mathrm{E}, \mathrm{M}}=\beta_{\mathrm{U}, \mathrm{M}}$. For the second case, the case with a taxation of a COD, I obtain

$$
\beta_{\mathrm{D}, \mathrm{M}}=\beta_{\mathrm{E}, \mathrm{M}} \times \frac{1+r^{\mathrm{f}} \times(1-\tau)}{R^{\mathrm{f}}(1-\tau)},
$$

in which $\frac{1+r^{\mathrm{f}} \times(1-\tau)}{R^{\mathrm{f}} \times(1-\tau)}>1$. For example for $r^{\mathrm{f}}=0.02$ and $\tau=0.3$ the term is about 1.4 so that $\beta_{\mathrm{D}, \mathrm{M}}$ has to be more than 1.4 times bigger than $\beta_{\mathrm{E}, \mathrm{M}}$ to obtain $\beta_{\mathrm{E}, \mathrm{M}}<\beta_{\mathrm{U}, \mathrm{M}}$.

For the pro rata case the debt beta for $\beta_{\mathrm{E}, \mathrm{M}}=\beta_{\mathrm{U}, \mathrm{M}}$ is

$$
\beta_{\mathrm{D}, \mathrm{M}}=\beta_{\mathrm{E}, \mathrm{M}},
$$

so that $\beta_{\mathrm{D}, \mathrm{M}}$ has to be greater than $\beta_{\mathrm{E}, \mathrm{M}}$ to obtain $\beta_{\mathrm{E}, \mathrm{M}}<\beta_{\mathrm{U}, \mathrm{M}}$.

For interest prioritization with the assumption of certain interest payments, I obtain

$$
\beta_{\mathrm{D}, \mathrm{M}}=\beta_{\mathrm{E}, \mathrm{M}} \times \frac{R^{\mathrm{f}}-\tau \times r^{\mathrm{c}}}{R^{\mathrm{f}}},
$$

in which $\frac{R^{\mathrm{f}}-\tau \times r^{\mathrm{c}}}{R^{\mathrm{f}}}=1-\tau \times r^{\mathrm{c}} / R^{\mathrm{f}}$ is less than one for $r^{\mathrm{c}}>0$. For example, for $r^{\mathrm{f}}=0.02, \tau=0.3$ and $r^{\mathrm{c}}=0.06$ the term is 0.98 . Thus, $\beta_{\mathrm{D}, \mathrm{M}}$ does not even have to be greater than the beta of unlevered equity for $\beta_{\mathrm{E}, \mathrm{M}}<\beta_{\mathrm{U}, \mathrm{M}}$.

The fifth equation treats principal prioritization. The equation requires the additional parameters $\alpha$ and $\beta_{\Delta \mathrm{TS}, \mathrm{M}}$. It was constructed so that the first part of the equation is the same as the equation for the pro rata case. Thus, the two additional terms in the equation for principal prioritization versus the equation for the pro rata case determine whether the resulting levered equity beta is greater, less than or equal to the levered equity beta for the pro rata distribution, when equal inputs are used. As was mentioned earlier, $\beta_{\Delta \mathrm{TS}, \mathrm{M}}>0$ is a reasonable assumption for principal prioritization. Furthermore, for a positive risk-free rate the term $\tau \times \frac{D}{S} \times$ $\left(\frac{r^{\mathrm{c}}}{R^{\mathrm{c}}}-\alpha \times \frac{r^{\mathrm{c}}-r^{\mathrm{f}}}{R^{\mathrm{f}}}\right)$ is always positive. Assuming that $\beta_{\mathrm{U}, \mathrm{M}}>\beta_{\mathrm{D}, \mathrm{M}}$, makes the two additional terms positive. This leads to a levered equity beta that is greater than the one under the assumption of a pro rata distribution.

I provide a simple numerical example with the objective to observe the potential error from picking the incorrect procedure, i.e., the incorrect equation, given that the betas for unlevered equity and for debt are known. For the example, I choose the following parameters: $\tau=0.3, \quad l=0.6 \quad$ (implying $D / S=1.5$ ), $\quad \beta_{\mathrm{U}, \mathrm{M}}=0.9$, $\beta_{\mathrm{D}, \mathrm{M}}=0.4, r^{\mathrm{f}}=0.02, \alpha=0.2, \beta_{\Delta \mathrm{TS}, \mathrm{M}}=0.3$ and $r^{\mathrm{c}}=0.06$. Table 2 shows that the betas for levered equity vary from 2.24 down to 1.63 . That would imply expected returns for unlevered equity from $15.45 \%$ down to $11.76 \%$ for this example. The table shows that picking the incorrect equation has the potential for substantial errors in discount rates, and thus for substantial misvaluations. Especially assuming risk-free debt when debt is actually risky has a big impact in this example because the additional term with the debt beta, which reduces the levered beta, is not used for risk-free debt. The assumption of a COD taxation also 
Table 2 Summary of cases and equations

\begin{tabular}{lllll}
\hline Risk & COD tax & Loss distrib. & $\beta_{\mathrm{E}, \mathrm{M}}$ & $E\left[R^{\mathrm{E}}\right](\%)$ \\
\hline Risk-free & NA & NA & 2.24 & 15.45 \\
Risky & Yes & Does not matter & 1.82 & 12.93 \\
& No & Pro rata & 1.64 & 11.82 \\
& & Interest prio. & 1.63 & 11.76 \\
& & Principal prio. & 1.65 & 11.87 \\
\hline
\end{tabular}

has a significant impact on the beta and the associated expected return. In turn, the figures presented without a COD taxation do not differ markedly. The reason is that for those equations and for a moderate risk-free rate as well as coupon rate, all the factors multiplied with $\beta_{\mathrm{E}, \mathrm{M}}$ and with $\beta_{\mathrm{D}, \mathrm{M}}$ do not differ a lot. Furthermore, the two additional terms in the equation for principal prioritization are small for reasonable parameters, such as the ones used in the example.

\section{Levered and unlevered beta in an infinite period setting with constant leverage}

I take a simple approach and assume constant leverage and independently and identically distributed (i.i.d.) returns. At any point in time and in any state debt and equity cash flows have the same return distribution. The risk-free rate is assumed to be constant. The firm issues only single-period debt. It adjusts debt and equity at each point in time to keep leverage constant. Even after a default leverage is kept constant by whoever is the (new) owner of the company.

The returns are now defined as $R_{t+1}^{\mathrm{E}}=\frac{\mathrm{ECF}_{t+1}+S_{t+1}}{S_{t}}$ for the return on levered equity, $R_{t+1}^{\mathrm{U}}=\frac{\mathrm{FCF}_{t+1}+V_{t+1}^{\mathrm{U}}}{V_{t}^{\mathrm{U}}}$ for the return on unlevered equity, and $R_{t+1}^{\mathrm{D}}=\frac{\mathrm{DCF}_{t+1}+D_{t+1}}{D_{t}}$ for the return on debt.

The following identity must hold at any time:

$$
\mathrm{ECF}_{t+1}+S_{t+1}+\mathrm{DCF}_{t+1}+D_{t+1}=\mathrm{FCF}_{t+1}+V_{t+1}^{\mathrm{U}}+\mathrm{TS}_{t+1}+\mathrm{VTS}_{t+1} .
$$

The identity holds the same way taking conditional expectations:

$$
\begin{aligned}
& E_{t}\left[\mathrm{ECF}_{t+1}\right]+E_{t}\left[S_{t+1}\right]+E_{t}\left[\mathrm{DCF}_{t+1}\right]+E_{t}\left[D_{t+1}\right] \\
& \quad=E_{t}\left[\mathrm{FCF}_{t+1}\right]+E_{t}\left[V_{t+1}^{\mathrm{U}}\right]+E_{t}\left[\mathrm{TS}_{t+1}\right]+E_{t}\left[\mathrm{VTS}_{t+1}\right] .
\end{aligned}
$$

I use the definitions of returns to obtain

$$
S_{t} \times E_{t}\left[R_{t+1}^{\mathrm{E}}\right]+D_{t} \times E_{t}\left[R_{t+1}^{\mathrm{D}}\right]=\left(S_{t}+D_{t}-\mathrm{VTS}_{t}\right) \times E_{t}\left[R_{t+1}^{\mathrm{U}}\right]+E_{t}\left[\mathrm{TS}_{t+1}\right]+E_{t}\left[\mathrm{VTS}_{t+1}\right] .
$$

I represent the value of the tax savings as discounted next period's tax savings and 
discounted next period's value of all future tax savings, in which I assign two different discount rates to the respective figures:

$$
\mathrm{VTS}_{t}=\frac{E_{t}\left[\mathrm{TS}_{t+1}\right]}{E_{t}\left[R_{t+1}^{\mathrm{TS}}\right]}+\frac{E_{t}\left[\mathrm{VTS}_{t+1}\right]}{E_{t}\left[R_{t+1}^{\mathrm{VTS}}\right]} .
$$

The first part, $\frac{E_{t}\left[\mathrm{TS}_{t+1}\right]}{E_{t}\left[R_{t+1}^{\mathrm{TS}}\right]}$, is the value of the tax savings of the next period. This value can be represented through the equations presented in the single-period modelonly the time subscripts need to be adjusted. The second part, $\frac{E_{t}\left[\mathrm{VTS}_{t+1}\right]}{E_{t}\left[R_{t+1}^{\mathrm{VTS}}\right]}$, is the value at time $t$ of all tax savings incurred after $t+1$. An important result of Miles and Ezzell (1985) is that for constant leverage the value of the tax shield is discounted at the discount rate for unlevered equity. Krause and Lahmann (2015) find that this is due to the tax shield value being proportional to the value of the unlevered firm when leverage is constant. They also find that the result holds in an i.i.d. setting with risky debt.

Since I assume constant leverage here, the equation for the tax shield value can be restated with $E_{t}\left[R_{t+1}^{\mathrm{VTS}}\right]=E_{t}\left[R_{t+1}^{\mathrm{U}}\right]$.

$$
\begin{aligned}
S_{t} & \times E_{t}\left[R_{t+1}^{\mathrm{E}}\right]+D_{t} \times E_{t}\left[R_{t+1}^{\mathrm{D}}\right] \\
& =\left(S_{t}+D_{t}-\left[\frac{E_{t}\left[\mathrm{TS}_{t+1}\right]}{E_{t}\left[R_{t+1}^{\mathrm{TS}}\right]}+\frac{E_{t}\left[\mathrm{VTS}_{t+1}\right]}{E_{t}\left[R_{t+1}^{\mathrm{U}}\right]}\right]\right) \times E_{t}\left[R_{t+1}^{\mathrm{U}}\right]+E_{t}\left[\mathrm{TS}_{t+1}\right]+E_{t}\left[\mathrm{VTS}_{t+1}\right],
\end{aligned}
$$

Simplifying, the equation condenses to the same equation as for the single period [Eq. (12)]:

$$
S_{t} \times E_{t}\left[R_{t+1}^{\mathrm{E}}\right]+D_{t} \times E_{t}\left[R_{t+1}^{\mathrm{D}}\right]=\left(S_{t}+D_{t}-\frac{E_{t}\left[\mathrm{TS}_{t+1}\right]}{E_{t}\left[R_{t+1}^{\mathrm{TS}}\right]}\right) \times E_{t}\left[R_{t+1}^{\mathrm{U}}\right]+E_{t}\left[\mathrm{TS}_{t+1}\right] .
$$

Thus, the same equations for the de- and re-levering procedures of betas must follow for the infinite horizon case with constant leverage in an i.i.d. world. Equations of Table 1 can also be applied for this case.

\section{Conclusion}

I provide equations to re- and de-lever betas under different assumptions regarding the riskiness of debt and the taxation of a COD. When a COD is not taxed, the distribution of losses on interest and principal payments becomes important. I look at five cases: the risk-free case, the risky case with a taxed COD, the risky case without a taxed COD and pro rata distributed losses, the risky case without a taxed COD and interest prioritization, and the risky case without a taxed COD and principal prioritization. I find that equations differ substantially so that the application of the incorrect procedure potentially leads to big errors in determining the discount rate. Additionally, the same equations for de- and re-levering betas for 
a single-period setting hold for a simple i.i.d. infinite horizon setting with constant leverage.

Open Access This article is distributed under the terms of the Creative Commons Attribution 4.0 International License (http://creativecommons.org/licenses/by/4.0/), which permits unrestricted use, distribution, and reproduction in any medium, provided you give appropriate credit to the original author(s) and the source, provide a link to the Creative Commons license, and indicate if changes were made.

\section{Appendix A-Derivation of de- and re-levering of betas with risk-free debt in a single period setting}

For risk-free debt

$$
\mathrm{VTS}=\tau \times \frac{r^{\mathrm{f}} \times D}{R^{\mathrm{f}}}
$$

and $R^{\mathrm{D}}=R^{\mathrm{f}}$ as well as TS $=\tau \times D \times r^{\mathrm{f}}$. Cash flows turn to

$$
S \times E\left[R^{\mathrm{E}}\right]+D \times R^{\mathrm{f}}=\left(S+D-\tau \times \frac{r^{\mathrm{f}} \times D}{R^{\mathrm{f}}}\right) \times E\left[R^{\mathrm{U}}\right]+\tau \times D \times r^{\mathrm{f}} .
$$

I use the expected return equation from the mean-variance CAPM for levered equity, i.e., $E\left[R^{\mathrm{E}}\right]=R^{\mathrm{f}}+\beta_{\mathrm{E}, \mathrm{M}} \times\left(E\left[R^{\mathrm{M}}\right]-R^{\mathrm{f}}\right)$, and for unlevered equity with $E\left[R^{\mathrm{U}}\right]=R^{\mathrm{f}}+\beta_{\mathrm{U}, \mathrm{M}} \times\left(E\left[R^{\mathrm{M}}\right]-R^{\mathrm{f}}\right)$. I substitute both into Equation (58) to obtain

$$
\begin{aligned}
S & \times\left(R^{\mathrm{f}}+\beta_{\mathrm{E}, \mathrm{M}} \times\left(E\left[R^{\mathrm{M}}\right]-R^{\mathrm{f}}\right)\right)+D \times R^{\mathrm{f}} \\
& =\left(S+D-\tau \times \frac{r^{\mathrm{f}} \times D}{R^{\mathrm{f}}}\right) \times\left(R^{\mathrm{f}}+\beta_{\mathrm{U}, \mathrm{M}} \times\left(E\left[R^{\mathrm{M}}\right]-R^{\mathrm{f}}\right)\right)+\tau \times D \times r^{\mathrm{f}} .
\end{aligned}
$$

Simplification leads to

$$
S \times \beta_{\mathrm{E}, \mathrm{M}} \times\left(E\left[R^{\mathrm{M}}\right]-R^{\mathrm{f}}\right)=\left(S+D-\tau \times \frac{r^{\mathrm{f}} \times D}{R^{\mathrm{f}}}\right) \times \beta_{\mathrm{U}, \mathrm{M}} \times\left(E\left[R^{\mathrm{M}}\right]-R^{\mathrm{f}}\right) .
$$

I divide by the equity premium and by $S$, which yields

$$
\beta_{\mathrm{E}, \mathrm{M}}=\left(1+\frac{D}{S} \times \frac{1+r^{\mathrm{f}} \times(1-\tau)}{R^{\mathrm{f}}}\right) \times \beta_{\mathrm{U}, \mathrm{M}} .
$$

\section{Appendix B-Higher beta with higher leverage under risk-free debt}

I add a prime symbol to the symbols of cash flows, values and returns after the debt increase. Assets remain the same. There are no taxes. I scale equity down by $\Delta$ so that $S^{\prime}=S-S \times \Delta$, with $1>\Delta>0$, and debt increases accordingly so that $D^{\prime}=D+\Delta \times S$. After the increase debt still remains risk-free. Equity cash flows change to $\mathrm{ECF}^{\prime}=\mathrm{ECF}-\Delta \times S \times R^{\mathrm{f}}$. That means a risk-free part of the equity cash flow goes away. It actually adds to debt cash flows. Debt cash flows change to 
$\mathrm{DCF}^{\prime}=(D+\Delta \times S) \times R^{\mathrm{f}}$. The return on equity before the change was $R^{\mathrm{E}}=\mathrm{ECF} / S$. Now it turns to $R^{\mathrm{E} \prime}=\left(\mathrm{ECF}-\Delta \times S \times R^{\mathrm{f}}\right) /(S \times(1-\Delta))$. Now, I look at the numerator of the equity beta which is a covariance of the form $\operatorname{Cov}\left(R^{\mathrm{E}}, R^{\mathrm{M}}\right)$. The denominator is the variance of the return on the market portfolio $\operatorname{Var}\left(R^{\mathrm{M}}\right)$ and does not change with the change in leverage. With the new return on equity the covariance turns to

$$
\begin{gathered}
\operatorname{Cov}\left(R^{\mathrm{E}^{\prime}}, R^{\mathrm{M}}\right)=\operatorname{Cov}\left(\frac{\mathrm{ECF}-\Delta \times S \times R^{\mathrm{f}}}{S \times(1-\Delta)}, R^{\mathrm{M}}\right) \\
=\operatorname{Cov}\left(\frac{\mathrm{ECF}}{S \times(1-\Delta)}-\frac{\Delta \times S \times R^{\mathrm{f}}}{S \times(1-\Delta)}, R^{\mathrm{M}}\right) \\
=\operatorname{Cov}\left(\frac{R^{\mathrm{E}}}{(1-\Delta)}, R^{\mathrm{M}}\right) \\
=\frac{1}{1-\Delta} \times \operatorname{Cov}\left(R^{\mathrm{E}}, R^{\mathrm{M}}\right) .
\end{gathered}
$$

The term $1 /(1-\Delta)$ is greater one so that the covariance is scaled up. That means, with a positive beta, increasing leverage increases the beta. A negative beta would be even more negative. However, this case is very unlikely for equity. This case would be like an insurance against market risk.

\section{References}

Arzac, E.R., and L.R. Glosten. 2005. A reconsideration of tax shield valuation. Eur Financial Manag 11 (4): 453-461.

Blaufus, K., and J. Hundsdoerfer. 2008. Taxes and the choice between risky and risk-free debt: on the neutrality of credit default taxation. Rev Manag Sci 2 (3): 161-181.

Cochrane, J.H. 2005. Asset pricing/revised edition. New Jersey: Princeton University Press.

Cooper, I.A., and K.G. Nyborg. 2008. Tax-adjusted discount rates with investor taxes and risky debt. Financial Manag 37 (2): 365-379.

Coval, J.D., and T. Shumway. 2001. Expected option returns. J Finance 56 (3): 983-1009.

IRS (2012) Publication 908-bankruptcy tax guide. https://www.irs.gov/pub/irs-pdf/p908.pdf. Accessed 20 Jan 2018.

Krause, M.V., and A. Lahmann. 2015. Reconsidering the appropriate discount rate for tax shield valuation. J Bus Econ Forthcom 86(5): 477-512.

Krause, M.V., and A. Lahmann. 2017. Valuation effects of taxes on debt cancellation. Quart Rev Econ Finance 65: 346-354.

Kruschwitz, L., and A. Löffler. 2006. Discounted cash flow-a theory of the valuation of firms, 1 st ed. Chichester: Wiley.

Miles, J.A., and J.R. Ezzell. 1980. The weighted average cost of capital, perfect capital markets, and project life: a clarification. J Financial Quant Anal 15 (3): 719-730.

Miles, J.A., and J.R. Ezzell. 1985. Reformulating tax shield valuation: a note. J Finance 40: 14851492.

Modigliani, F., and M.H. Miller. 1958. The cost of capital, corporation finance and the theory of investment. Am Econ Rev 48 (3): 261-297.

Modigliani, F., and M.H. Miller. 1963. Corporate income taxes and the cost of capital: a correction. Am Econ Rev 53 (3): 433-443.

Schwartzman RA, Brandstetter P (2015) Tax considerations for cancellation-of-debt income. The tax advisor. https://www.thetaxadviser.com/issues/2015/may/tax-clinic-06.html. Accessed 20 Jan 2018. 